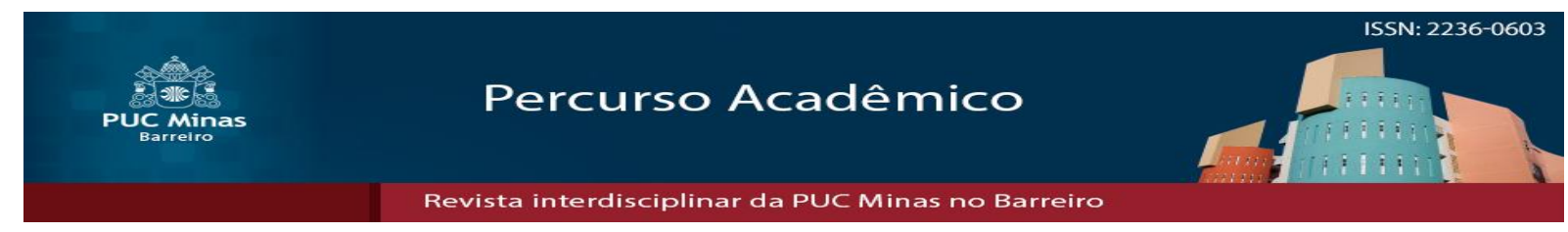

\title{
Crítica marxista à teoria geral do direito burguês à luz da teoria pachukaniana
}

\author{
Marxist critique of the general theory of bourgeois law in the light of \\ Pachukanian theory
}

Leandro Victor Rodrigues*

\section{Resumo}

Este trabalho trata de uma análise crítica à teoria geral do direito burguês à luz da perspectiva pachukaniana. Nesse sentido, o objetivo do presente trabalho é investigar e analisar os elementos centrais da teoria geral do direito burguês à luz da perspectiva pachukaniana, para apontar as contradições e a necessidade de superação da superestrutura jurídica. Em razão disso, o foco da presente investigação e análise foi na equivalência identificada entre a forma-mercadoria e a forma jurídica, e também, na relação contraditória que surge entre a forma-mercadoria e sujeito de direito; direito e poder estatal; entre a moral e o pensamento jurídico burguês e entre a norma objetiva e relação jurídica. Para tanto, a metodologia utilizada foi a revisão bibliográfica da obra de Pachukanis, que utilizou o mesmo método que Marx, em Introdução à Economia Política. Ao final, pôde-se concluir que, devido às contradições que surgem da superestrutura jurídica, é necessária a superação tanto do direito como do Estado para a emancipação e libertação do homem.

Palavras-chave: Forma-mercadoria. Forma jurídica. Superestrutura jurídica. Moral e pensamento burguês. Norma e relação jurídica

\begin{abstract}
This paper is a critical analysis of the theory of bourgeois law pursuant to pachukanian perspective. Therefore, the current work aims to investigate and analyze the core elements of the general theory of bourgeois law pursuant to pachukanian perspective, to point out the contradictions and the needs of overcoming the legal superstructure. For this reason, the focus of the present investigation and analysis was kept on the identified equivalence between the commodity-form and the legal form and, also, on the contradictory relationship that arises between the commodity-form and the subject of law; law and state power; between morality and bourgeois legal thinking and between the objective norm and legal relationship. Therefore, the applied methodology was a bibliographic review of Pachukanis' work, who used the same method as Marx, in Introduction to Political Economy. In the end, it is concluded that, due to the contradictions that arise from the legal superstructure, it is necessary to overcome both the law and the State for the emancipation and liberation of man.
\end{abstract}

Keywords: Commodity-form. Legal form. Legal superstructure. Moral and bourgeois thinking. Norm and legal relationship.

Artigo recebido em 31 de Agosto de 2018 e aprovado em 13 de Dezembro de 2018 *Graduando em Direito pela Pontifícia Universidade Católica de Minas Gerais. Brasil. E-mail: leandro.jus.adjr@gmail.com 


\section{Introdução}

No início do século passado, Evguiéni B. Pachukanis, em meio à revolução russa, surge com uma voz dissonante em relação ao desenvolvimento do assim chamado "Estado operário". Para ele, o partido bolchevique estava cometendo um grande erro em afirmar a tese de que seria viável a promoção de uma concepção socialista com base na produção estatal.

Pachukanis percebeu que não bastava apenas a eliminação dos interesses privados, uma vez que as empresas estatais estariam sujeitas às condições de circulação, ou seja, a eliminação do interesse privado não eliminará por completo a forma-mercadoria, e, em razão disso, as relações das empresas estatais ainda seriam demarcadas pela superestrutura jurídica.

Mas, para concluir esse raciocínio, Pachukanis não delimitou seu objeto de estudo em relação ao próprio conteúdo do direito, mas, sim, em relação a sua forma. Feito isso, Pachukanis descobriu que havia uma equivalência da forma-mercadoria com a forma jurídica, e que, na verdade, a origem da forma jurídica guardava uma íntima relação com os meios de produção.

Com isso, Pachukanis rompeu com o que tinha sido proposto por Stutchka e Mikhail Reisner em relação à crítica ao direito, uma vez que ele realizou uma crítica que foi pensada e desenvolvida levando em consideração a mesma metodologia empregada por Marx, em Introdução à Crítica da Economia Política.

Assim, dialeticamente, analisou as categorias gerais e concretas, e simples e complexas. Nessa lógica, o foco da crítica marxista à teoria geral do direito burguês à luz da teoria pachukaniana, além da crítica à metodologia burguesa, será em demonstrar a equivalência existente entre a forma jurídica e a forma-mercadoria.

Para isso, discorrer-se-á sobre os seguintes tópicos:

a) Em um primeiro momento, analisar-se-á de perto a categoria sujeito de direito e suas contradições em relação à autodeterminação do homem, pois, não raro, os exemplos em que, na verdade, tal categoria o tornou ainda mais escravo;

b) Na sequência, analisar-se-á a relação entre o direito e o poder estatal e, com isso, demonstrar-se-á que ambos possibilitaram o desenvolvimento da forma-mercadoria. Porém, para isso, tanto o direito quanto o poder estatal carregam uma imagem dúbia; 
c) Em terceiro, analisar-se-á a moral e o pensamento jurídico burguês, pois a categoria do sujeito moral imanado com o imperativo categórico de Immanuel Kant contribuiu para a expansão do sujeito de direito e, consequentemente, do Estado capitalista;

d) Por último, analisar-se-á a relação entre a norma em sentido objetivo e relação jurídica, e demonstrar-se-á que, ainda que se pense que a relação jurídica somente decorre da norma em sentido objetivo, ela é determinada pela forma-mercadoria.

\section{Crítica à construção da ciência jurídica burguesa}

O ponto de partida de uma crítica marxista à teoria geral do direito burguês passa-se, desde logo, pela crítica à metodologia empregada pelos juristas burgueses, pois a grande maioria deles desenvolveu a ciência jurídica fora dos limites da realidade concreta. Em razão disso, em Teoria Geral do Direito e Marxismo, Pachukanis irá propor uma abordagem crítica à forma jurídica burguesa.

Para tanto, Pachukanis lançará mão dos princípios metodológicos empregados por Karl Marx, em Introdução à Crítica da Economia Política, pois ele observou que havia uma equivalência entre a forma jurídica e a forma-mercadoria e, por sua vez, a necessidade de superação desta forma de ser do direito, uma vez que o autor considerava irreconciliável que tal forma jurídica fosse adotada pelos bolcheviques. (NAVES, 2008).

Depreende-se então que o fenômeno jurídico tem sua fase embrionária nas contradições que emergem das relações privadas, isto é, não surge como mera abstração, mas como situações correspondentes a uma forma de ser social e historicamente definida pelo modo de produção capitalista, tanto que, sem a atomização do direito, a sociedade capitalista não se sustentaria por muito tempo.

Por outro lado, segundo Paulson, em Fundamentación Crítica de la Doctrina de Hans Kelsen, desde o início o trabalho de Kelsen foi desenvolvido no sentido contrário das filosofias tradicionais de sua época, assim rompendo com as correntes "empíricas ou sociológicas" e "jusnaturalistas". Estas porque partiam de postulados ético-políticos, aquelas porque tomavam a lei como fração da própria realidade. (STANLEY, 2000).

Em relação a isso, observa-se que já no início de sua obra, Teoria Pura do Direito, Hans Kelsen afirma que: 
Como teoria, quer única e exclusivamente conhecer o seu próprio objeto. Procura responder a esta questão: o que é e como é o Direito? Mas já não importa a questão de saber como deve ser o Direito, ou como deve ele ser feito. É ciência jurídica e não política do Direito.” (KELSEN, 1987, p.1).

Deste modo, Kelsen propõe uma teoria normativista e formalista, que visa afastar a ciência jurídica da realidade por meio do emprego exclusivo da lógica formal. Percebe-se, então, que a teoria pura do direito parte de uma cadeia dedutiva de normas superiores e inferiores, as quais devem ser operacionalizadas dentro um padrão lógico-formal.

Daí, portanto, a razão cuja crítica e metodologia de Pachukanis concentraram-se na forma jurídica, diferentemente do que vinha sendo adotado por P. Stutchka, uma vez que este tinha apenas introduzido o direito da classe trabalhadora na concepção burguesa do direito, mas, segundo Pachukanis, isso não é suficiente para solucionar os impasses com a concepção burguesa do direito.

Ademais, é possível estabelecer uma correlação entre o que é proposto por Pachukanis e Sartori. Este, em Lukács e a Crítica Ontológica ao Direito, defende a necessidade de uma análise do fenômeno jurídico, além do sujeito cognoscente, isto é, para uma análise genuína do direito, se faz necessário romper com os limites do racionalismo exacerbado. (SARTORI, 2013).

Sartori desenvolverá o raciocínio no sentido de que tanto a abordagem dogmática quanto a zetética da ciência jurídica originam-se de meras evidências (SARTORI, 2013). Sobre isso ele afirma que:

Se a zetética parte de evidências enquanto a dogmática parte de premissas ainda problematizáveis, ou seja, de dogmas, como poderia esta contraposição ser tão decisiva? Como poderia, concomitantemente, a interpretação do fenômeno jurídico ser dada com precisão se as diferentes abordagens tomam por base justamente a "evidência"? Quem define esta "evidência"? Será ela histórica e social, ou não?" (SARTORI, 2013). [E-Book].

Ou seja, a suspeita não recai apenas no desenvolvimento do direito posto ou direito material, mas integra até mesmo a zetética, uma vez que ela também surge através das evidências. Uma advertência, portanto, deve ser feita, ela é: será que o jusfilósofo, enquanto sujeito histórico, não seria influenciado por uma história real. (SARTORI, 2013).

E com o intuito de romper com a lógica burguesa do direito, Pachukanis conduzirá à análise correlacionando as categorias do presente e do passado, pois aquelas possuem o 
substrato para a compreensão desta, porque o estágio mais avançado da forma jurídica revela a ligação entre a forma jurídica e a forma-mercadoria. (NAVES, 2008).

Logo, feita essa breve introdução dos aspectos da metodologia empregada por Pachukanis, a seguir, a análise se dará acerca da relação existente entre: a forma-mercadoria e o sujeito de direito; direito e o poder estatal; a moral e o pensamento jurídico burguês e a relação entre norma objetiva e relação jurídica. Sendo aquela, a primeira a ser analisada.

\section{A relação forma-mercadoria e sujeito de direito}

A forma-mercadoria e a forma jurídica possuem os elementos necessários para o desenvolvimento e circulação de mercadorias na sociedade capitalista. Por essa razão, para Pachukanis, a análise da forma jurídica deveria partir da noção do conceito de sujeito de direito. Nesse sentido, ele afirma que: “[...] Toda relação jurídica é uma relação entre sujeitos [...]". (PACHUKANIS, 2017, P. 117),

Tal afirmação é sustentada pelo fato de que, com o desenvolvimento das relações mercantis, a propriedade privada adquiriu a sua forma e sentido contemporânea, quer dizer: além de possuir bens, o indivíduo poderia também aliená-los. Logo, esta é a razão central pela qual Pachukanis começa a sua análise da forma jurídica pelo conceito de sujeito de direito e não pela posse.

Para tanto, Pachukanis afirma que:

Não penso, evidentemente, em negar essa ligação, afirmo apenas que a propriedade se torna fundamental para o desenvolvimento da forma jurídica somente enquanto livre disposição no mercado, e a expressão mais geral dessa liberdade é desempenhada pela categoria de sujeito. (PACHUKANIS, 2017, p.118).

Verifica-se então que o mérito da teoria marxista foi em identificar que o título jurídico, tal qual, ao proprietário de mercadorias, permitiu que o proprietário de terras procedesse com as mesmas, por isso que o servo deixou aquela relação de dominação e escravidão, tendo em vista que antes não havia a mediação de uma forma jurídica desenvolvida.

Por outro lado, tal passagem contribuiu à outra forma de exploração, a saber: o trabalho como mercadoria. Nesse sentido, Naves (2008) argumenta que, até então, a mercadoria era um fenômeno distinto do trabalho, porém isso teria mudado com o advento da noção de sujeito de direito, isto é, o trabalho também se tornou uma mercadoria. Dessa forma, 
percebe-se que tal fenômeno é típico da sociedade burguesa em seu estágio de desenvolvimento.

Aqui cabe citar uma distinção feita por Marx, em Miséria da Filosofia, em resposta à "Filosofia da Miséria" de Pierre-Joseph Proudhon. Proudhon chegou a propor que comprador e produtor são livres na realização da troca de mercadorias. Em suas próprias palavras, ele diz:

Em minha qualidade de comprador livre, sou árbitro de minha necessidade, o árbitro da conveniência do objeto, o árbitro do preço que eu quero pagar por êle (sic). Por outra parte você, na qualidade de produtor livre, é dono dos meios de preparação do objeto e, por conseguinte tem a faculdade de reduzir seus gastos. (PROUDHON apud MARX, 1965, p. 38).

Ao contrário, Marx demonstrará que o produtor e comprador contarão com os meios obtidos por meio de troca para tornar efetiva a realização de troca de mercadorias, ou seja, dado o desenvolvimento da sociedade capitalista, o produto não pode ser considerado útil por si mesmo e nem mesmo será exclusivamente útil segundo a vontade do comprador. (MARX, 1965)

Marx conclui dizendo: “[...] Portanto, na oferta e na procura encontramos, de um lado, um produto que custou valôres (sic) de troca e a necessidade de vender; de outro lado meios que custaram valôres (sic) de troca e o desejo de comprar [...]" (MARX, 1965, p. 40).

Esse conjunto de ideias apresentadas demonstra que, na verdade, por parte do comprador, sua posição social determina suas escolhas, e mais: isso é fruto de um conjunto de elementos da organização social; por outro lado a oferta surge de uma série de fatores que têm como fundamento a própria produção. Por tudo isso, não há que se atribuir arbítrio aos sujeitos da relação, porque isso é subtraído pela totalidade das relações de produção e perpetuado pela forma jurídica.

Em oposição a isso, Pachukanis colocará em xeque o direito burguês de sua época, pois, para ele, a forma jurídica da classe dominante limita a noção de sujeito de direito aos seus aspectos formais, e, consequentemente, negligencia os fatos históricos que suplantaram a estrutura da sociedade feudal e fizeram dos homens de meros escravos a sujeitos de direito.

Nota-se a definição de sujeito de direito trazida por Hans Kelsen, em Teoria Pura do Direito.

Dizer que o homem é sujeito jurídico, isto é, sujeito de direitos e deveres, não significa - como foi expressamente acentuado acima - senão que a conduta humana 
é conteúdo de deveres jurídicos e direitos subjetivos, e, portanto, o mesmo que dizer que um homem é pessoa ou tem personalidade. (KELSEN, 1987, p. 186).

Aqui, fica claro que a sua definição de sujeito de direito leva em consideração somente os aspectos formais, uma vez que pressupõe que a relação jurídica já está dada de antemão. É uma construção puramente epistemológica porque em nenhum momento ela abarca os entes em suas realidades concretas. Desse modo, não distingue os sujeitos de direito, assim se limitando a tratá-los por uma mera igualdade formal.

Em vista dos argumentos apresentados, se, e somente se, observados por uma perspectiva dialética, percebe-se que a totalidade das relações econômicas e jurídicas dilui os indivíduos em suas particularidades, porque, na verdade, os aspectos que dominam tais relações já estão preestabelecidos nas abstrações da disciplina da política econômica e das normas jurídicas.

Nesse sentido, Naves afirma que:

Ora, se a liberdade, esse atributo da personalidade, existe por e para a troca, isto é, para que se constitua um circuito de transações mercantis, então o homem só é livre uma vez inserido na esfera da circulação. Se, portanto, é a troca que constitui a liberdade do homem, podemos dizer que quanto mais se alarga a sua esfera de comercialização, mais livre então pode ele ser, de tal modo que a expressão a mais "acabada", a mais completa, a mais absoluta de sua liberdade, é a liberdade de disposição de si mesmo como mercadoria. (NAVES, 2008, p.67).

E conclui:

Aqui podemos encontrar o homem reduzido à sua "essência": no ato de troca de si mesmo o homem realiza a sua liberdade, portanto, a liberdade do homem aparece no ato de disposição de si como mercadoria, no qual o homem se torna um proprietário que carrega em si, em sua "alma", o objeto de seu comércio, um proprietário que realiza em si mesmo a qualidade de sujeito e de objeto de direito: $\mathrm{O}$ direito subjetivo sendo direito da pessoa e não encontrando a sua eficácia a não ser no consentimento, põe a relação vontade-liberdade do seguinte modo: a liberdade do homem é o seu livre consentimento. (NAVES, 2008, p. 67).

Tudo isso está acontecendo de forma simultânea ao crescimento da organização da sociedade. Com isso, a transformação do modelo econômico, a possibilidade da divisão do trabalho, as sucessivas trocas de mercadorias por sujeitos equivalentes e a equivalência entre a forma-mercadoria e a forma jurídica levaram ao desabrochar do Estado burguês.

Percebe-se então uma mutação da forma-mercadoria, pois os grandes capitalistas já não dependem tanto da forma jurídica, uma vez que o seu lucro está intimamente ligado ao 
consumo improdutivo. Identifica-se também que a grande massa do capital é agora gerenciada por um grupo seleto, que, através de pessoas jurídicas, controlam todo o jogo financeiro.

Assim, levando-se em conta o que foi observado, pode-se inferir que a capacidade de ser sujeito de direito só é suficiente para promover a autodeterminação formal, isto quer dizer que, embora ela diga que todos os homens são dignos dos mais variados direitos, por outro lado não criou nenhum mecanismo para que isso se torne algo efetivo. (PACHUKANIS, 2017).

Por último, a tarefa que fica é: a classe trabalhadora deverá criar mecanismos para superar a forma-mercadoria e a forma jurídica, porque enquanto uma perdurar; a outra será uma conditio sine qua non. Contudo, para isso, além de identificar, combater e superar a forma-mercadoria e forma jurídica, também deve-se compreender a relação que existe entre o direito e o poder estatal.

\section{Direito e o poder estatal}

Para muitos, o direito é o oposto do arbítrio, mas, por uma perspectiva indutiva, podese admitir o contrário. Por isso, a relação jurídica é simplesmente um meio que possibilita a união de dois ou mais sujeitos, mas não quer dizer que tal relação pressupõe total ausência de conflito. Nesse sentido, Karl Marx, em Grundrisse, definirá que: “[...] o direito do mais forte também é um direito [...]” (MARX, 2011). [E-Book].

Assim, percebe-se que a ordem jurídica é uma consequência, ou, no máximo, uma conjetura muito remota da relação jurídica, isto é, ela nunca deve ser entendida como o pressuposto desta. Nessa lógica, Pachukanis afirma que:

\footnotetext{
As empresas do Estado soviético executam, de fato, uma única tarefa coletiva, mas, ao trabalhar com o método de mercado, cada uma delas tem seu interesse particular, opondo-se umas às outras como compradoras e vendedoras, agindo por sua conta $\mathrm{e}$ risco, e por isso, devem necessariamente se encontrar em uma relação jurídica. (PACHUKANIS, 2017, p.139).
}

Ou seja, a análise do fenômeno jurídico supramencionado é, antes de tudo, uma análise que deve ladear as contradições que surgem em meio às relações jurídicas e econômicas. Logo, se tomadas como relações ordenadas, as contradições são encobertas e, com isso, a ordem jurídica confunde-se com o direito. 
No direito internacional, tal questão é levantada na maioria dos manuais. Francisco Rezek, por exemplo, traz a sua concepção quanto ao assunto:

\footnotetext{
No plano internacional não existe autoridade superior nem milícia permanente. Os Estados se organizam horizontalmente, dispostos a proceder de acordo com certas regras na exata medida em que estas tenham constituído objeto de seu consentimento. (REZEK, 2014, p. 23).
}

Observa-se então que, no plano internacional, a ordem jurídica não é um pressuposto para o surgimento do direito, na verdade, o que prevalece em muitas situações é: o direito do mais forte, a retaliação, a guerra etc. Portanto, o pensamento jurídico pachukaniano entende a ordem jurídica somente como uma tendência que se erige sob uma bruma de imperfeições.

Dito isso, é importante adentrar em alguns aspectos do desenvolvimento do Estado capitalista. Para Pachukanis, havia uma condição necessária para que a forma-mercadoria pudesse se desenvolver e assim estabelecer de forma contínua a relação de equivalência entre os sujeitos de direito. Para tanto, seria necessária a garantia da paz e da ordem, porque esta é uma condição necessária para o comércio.

Sobre isso, Pachukanis afirma que:

\begin{abstract}
Naqueles casos em que as condições para a manutenção da paz eram demasiado insignificantes, aqueles que trocavam a mercadoria preferiam não se encontrar pessoalmente, mas analisar as mercadorias sem a presença uns dos outros. Todavia, o comércio exige, em geral, que não apenas as mercadorias se encontrem, mas também as pessoas. (PACHUKANIS, 2017, p.140).
\end{abstract}

É nessa época que surge uma função que não lhes era devida, porque, para garantir o cumprimento dos negócios, eles se tornaram responsáveis em manter a paz, assim não havia limitação entre a esfera pública e privada. (PACHUKANIS, 2017).

Tardiamente, tal limitação foi alcançada, ao passo que o Estado capitalista se desenvolvia. Em razão dessas rupturas, a forma-mercadoria como forma reguladora das relações mercantis entre os sujeitos de direito foi ampliada, e com o avanço do comércio surge a economia monetária. (PACHUKANIS, 2017).

Portanto, pode-se inferir que a dominação da classe burguesa é abrangente e a sua influência ultrapassa os limites do aparato estatal, ela está presente de maneira ordeira e não ordeira, de tal forma que o Estado capitalista encontra-se em uma relação de sujeição ao mercado financeiro, aos bancos, as mineradoras e aos grandes grupos de capitalistas. 
Para Engels, todo este desenvolvimento surgiu em razão dos conflitos entre a classe burguesa e a classe do proletariado, pois, entre as suas várias funções, o Estado em seu sentido moderno burguês ergue-se para não permitir o aniquilamento da sociedade. Ele afirma que:

Mas para que esses antagonismos, essas classes com interesses econômicos colidentes, não se devorem e não consumam a sociedade numa luta estéril, faz-se necessário um poder colocado aparentemente por cima da sociedade, chamado a amortecer o choque e a mantê-lo dentro da "ordem". (ENGELS, 1984, p.191).

Mais adiante, Pachukanis diverge da seguinte afirmação de Engels: “[...] O Estado da classe mais poderosa, da classe economicamente dominante, classe que, por intermédio dele, se converteu também em classe política [...]”. (ENGELS, 1984, p.193).

Esta afirmação, para Pachukanis, expressa o seguinte absurdo: se o Estado é supraclasse, então poderá ser aceito que seu aparecimento trouxe correlação de força entre as classes. Entretanto, tal concepção não pode ser admitida; por outro lado, se ele levou a classe dominante ao poder, logo o Estado capitalista perde o seu papel e a sua razão de ser. (PACHUKANIS, 2017).

Para a leitura pachukaniana, há que se indagar por que a forma de domínio burguesa não se revela como tal, mas somente como poder de coerção sob a figura estatal, isto é: não deixa claro que parte do povo vive em uma relação de sujeição à outra parte. Porém, adverte que tal análise não pode deter-se somente nas representações ideológicas, pois não há correspondência com a realidade da qual origina a dominação de classe.

Nesse sentido, pode-se observar que a "vontade geral" tão proclamada pelo Estado liberal, na verdade é simplesmente um pretexto para camuflar a real personificação do Estado, que, de fato, representa um mercado. Logo, este mercado é sustentado pela força impessoal que trabalha para tornar viável a troca de mercadorias entre os sujeitos de direito.

Dessa forma, a vontade de um indivíduo sobre o outro é conferida ao poder do direito, assim se tem, por definição, um caráter impessoal e abstrato. Em certa medida, o pensamento jurídico burguês foi fomentado pela teoria do direito natural, pois tal teoria já predicava a noção de seres independentes e iguais, isto é, equivalentes aos possuidores de mercadorias.

Portanto, é cômoda tal concepção de Estado para a classe dominante, pois a vontade geral, na verdade, é a pura expressão do mercado erigido sob uma máscara ideológica, o que não era possível no Estado teocrático. Por isso, o Estado capitalista é, de fato, uma mera ficção de proposições que não encontram nenhuma conexão com a realidade. 
Pachukanis afirma que:

\begin{abstract}
Como se sabe, Lorenz Stein contrapôs o Estado ideal, que se está acima da sociedade, ao Estado absorvido pela sociedade - ou seja, em nossa terminologia, o Estado de classes. Como tal, ele classificou o Estado Feudal absolutista como o guardião dos privilégios dos grandes proprietários de terra e o capitalista como aquele que protege os privilégios da burguesia. Excluindo essas realidades históricas, resta apenas o Estado como a fantasia de um funcionário prussiano ou como a garantia abstrata das condições de trova (sic) baseadas no valor. (PACHUKANIS, 2017, p.148).
\end{abstract}

Ou seja, o "Estado de direito", Estado que é autônomo em relação à sociedade, só existe enquanto negação de si mesmo. Nesse sentido, Marx afirmará que o Estado é: “[...] um comitê para gerir os negócios comuns de toda a classe burguesa [...]”. (ENGELS; MARX, 2005, p. 42).

Logo, a investigação nos mostrou que a teoria burguesa do Estado nega a realidade da qual origina o próprio Estado. Em outras palavras, a teoria não dá à devida atenção as inúmeras relações de dependência que existem entre os sujeitos de direito ou possuidores de mercadorias.

Levando-se em conta o que foi observado, a visão burguesa do direito e do Estado é ambígua, pois ambos não dão conta de responder se eles estão a serviço da maioria ou não. $\mathrm{O}$ Estado, não somente porque esconde a real definição da "vontade geral", mas porque oculta as disputas pelas quais a sociedade está embrenhada. Já o direito porque é apresentado sob a forma de uma cadeia lógica de normas, quando, na verdade, é garantidor do interesse dos detentores dos meios de produção. É bem verdade que a sociedade burguesa não se valeu somente do sujeito de direito, Estado e sua força, mas também da moral.

\title{
5 A moral e o pensamento jurídico burguês
}

Para compreender o homem moderno é, antes de tudo, necessário dizer que ele é possuidor de três características: ele é sujeito de direito, sujeito moral e sujeito egoístico. Em primeiro lugar, é sujeito de direito porque pode realizar atos de troca. Em segundo lugar, é sujeito moral porque possui autodeterminação, à medida que é igual aos outros sujeitos e, em terceiro lugar, ele é sujeito egoístico porque no ato da troca age com o fim de maximizar o lucro. 
Para Pachukanis, tais características são necessárias para manter a sociedade mercantil de pé, muito embora elas sejam opostas umas às outras quando analisadas sob a perspectiva do mundo do dever ser.

Nesse sentido, Pachukanis afirma que:

\begin{abstract}
Se retirarmos essas definições daquela relação social real que elas expressam e tentarmos desenvolvê-las como categorias independentes, ou seja, puramente racionais, então teremos como resultado um emaranhado de contradições e de posições que se anulam mutuamente. Mas, na relação de troca real, essas contradições se conectam dialeticamente como uma totalidade. (PACHUKANIS, 2017, p.154).
\end{abstract}

Dito isso, a análise do sujeito moral merece uma atenção especial, pois, ao longo da história, observa-se que se discutiu muito sobre a igualdade entre os homens, no entanto, embora tenham surgido inúmeras definições sobre o tema, a desigualdade reinou e triunfou por muitos cantos da terra. Por exemplo, na Roma antiga, Sêneca chegou a dizer que se o corpo não fosse livre, pelo contrário, a alma permanecia livre. (PACHUKANIS, 2017).

Então, qual seria o motivo pelo qual nenhuma dessas definições foi capaz de trazer uma igualdade material, mas tão somente formulações vazias e abjetas? Para Pachukanis, a resposta a essa questão passa-se pela análise do sujeito moral, assim como foi perquirida a análise da categoria do sujeito de direito, isso quer dizer que a forma do sujeito moral também guarda equivalência com a forma-mercadoria.

A resultante disso é que a própria estrutura da sociedade capitalista possibilita a interpretação do sujeito moral e, por outro lado, revela, ao mesmo tempo, a contradição de seu conteúdo. É por isso que Pachukanis começa a análise do sujeito moral pelo imperativo categórico de Kant, dado a sua importância para a filosofia moral moderna e a influência de sua filosofia frente ao pensamento burguês.

De início, Pachukanis demonstra que o imperativo categórico está situado fora de qualquer experiência humana, isto é, lhe foi dado uma roupagem apenas formal e, por isso, fora desse contexto tal forma seria contraditória.

Sobre isso, ele afirma que:

Se a pessoa moral não é outra coisa senão o sujeito da sociedade de produção mercantil, então a lei moral deve se descobrir como a regra da sociedade de possuidores de mercadoria. Isso lhe confere, inevitavelmente, um caráter antinômico. Por um lado, essa lei deve ter um caráter social e, como tal, colocar-se acima da personalidade individual. Por outro lado, o possuidor de mercadorias, devido à própria natureza, é o portador da liberdade (da liberdade de apropriação e 
alienação); portanto, a regra que determina as relações entre possuidores de mercadoria deve ser implantada na alma de cada um deles, ser sua lei interna. (PACHUKANIS, 2017, p.155)

Recobra-se então um agir supra-individual e, ao mesmo instante, afirma-se que ele não depende e nem sofre força externa; por assim dizer, seria a consciência de todos operando em um. Contudo, na perspectiva moral pachukaniana, um dever moral não tem possibilidade de coexistir dentro desses limites.

A seguir, percebe-se que o imperativo categórico também destoa da ética Aristotélica. Alysson Leandro Mascaro, em Filosofia do Direito, afirma que:

Para Kant, ao contrário de Aristóteles, a equidade, ou seja, a adaptação ao caso concreto, não é o elemento ético mais alto. A universalidade do imperativo categórico é inabalável, e, portanto, não olha para as circunstâncias. Não mentir é um imperativo que não se altera moralmente a depender do caso concreto. (MASCARO, 2016). [E-Book].

Contudo, para Pachukanis, apenas a ética que respeita as variáveis do mundo do ser pode dissipar a ambiguidade do imperativo categórico. Nessa lógica, Pachukanis correlaciona o mínimo ético do direito, de Schopenhauer e V. Solovior, e, com base nisso, afirma que: "[...] pode-se definir a ética como um mínimo social. Um aumento na intensidade do sentimento de responsabilidade social situa-se fora da ética em sentido estrito [...]". (PACHUKANIS, 2017, p.157).

Dessa forma, a "liberdade" kantiana, como tal, reproduz o total isolamento do ser e se nivela à mesma "liberdade" dada aos camponeses, como relata Marx, em A Ideologia Alemã, que culminou com o deslocamento de grande parte dos camponeses para as cidades, assim marcando a oposição entre a cidade e o campo.

\footnotetext{
A oposição entre a cidade e o campo só pode existir nos quadros da propriedade privada. É a expressão mais crassa da subsunção do indivíduo à divisão do trabalho, à uma determinada atividade que lhe é imposta - subsunção que converte uns em limitados animais urbanos e outros em limitados animais rurais, reproduzindo diariamente a oposição entre os interesse de ambos. O trabalho volta a ser aqui o fundamental, o poder sobre os indivíduos, e enquanto existir esse poder deve existir a propriedade privada. (ENGELS; MARX, 1986, p.78).
}

Isso explica que as sociedades que precederam ao desenvolvimento do capitalismo, aos poucos, realizaram a transição para uma ética universalista. Com efeito, esse momento da universalização do sujeito moral coincide, em certa medida, com o surgimento do sujeito de 
direito. Para Pachukanis, isso refletia a conquista material obtida pela expansão do mercado. (PACHUKANIS, 2017).

Dessa forma, se a ética universalista deforma a realidade, então ela descontrói as relações e costumes locais, assim limitando o homem a uma igualdade formal. Nessa lógica, o sujeito, em particular, não é livre, mas goza de uma "certa liberdade". Conclui-se então que o capitalista é "ético" para com o trabalhador, porque este é "livre" para assinar o contrato.

Além disso, na práxis diária, a máxima:

Age de tal maneira que uses a humanidade, tanto na tua pessoa como na pessoa de qualquer outro, sempre e simultaneamente como fim e nunca // simplesmente como meio. (KANT, 2007). [E-Book].

Não é assimilada como desejado pelo autor, pois, diferentemente do mundo do dever ser, o outro, muitas vezes, é posto como meio e nunca como fim. (PACHUKANIS, 2017). Além do que, percebe-se que no interior do sujeito moral revela-se outra contradição em relação à forma ética, i.e., a noção do direito como dever ser, pois, se assim o fosse, não haveria a necessidade do direito em sua forma prescrita.

Por isso, Pachukanis afirma que:

\begin{abstract}
A conduta moral contrapõe-se à conduta jurídica, que se caracteriza como tal independentemente dos motivos que a geraram. Se a dívida será paga porque, "de todo modo, o devedor será forçado a pagá-la" ou porque o devedor se sente moralmente obrigado a fazê-lo, isso é absolutamente indiferente do ponto de vista jurídico. (PACHUKANIS, 2017, p.162).
\end{abstract}

Então, qualquer medida que queira superar a forma ética deverá buscar a transformação da sociedade de mercado para uma sociedade que planifique as relações entre os indivíduos.

Contudo, enquanto não ocorrer tal transformação, a massa do proletariado deverá lutar pela substituição do conteúdo da forma ética, pela proposição que exorta o sujeito moral a agir com fim de maximizar o interesse do proletariado. Até porque, com isso, ela não recusa a necessidade de superá-la, mas, já entende que, neste estágio, a classe do proletariado já tem chances de enfrentar a lógica da mercadoria.

Mas, para tal transformação, além da substituição do conteúdo da forma ética, a classe operária deverá superar a noção de relação jurídica, pois todos esses elementos agem em benefício da mesma estrutura. Não é à-toa que eles inverteram a lógica ao afirmarem que a norma é o pressuposto da relação jurídica. 


\title{
6 Norma objetiva e relação jurídica
}

A relação jurídica é determinada pela norma em seu sentido objetivo, ou então ela seria determinada por outros fatores. Para Pachukanis, "[...] o poder estatal confere clareza e estabilidade à estrutura jurídica, mas não cria seus pressupostos, os quais estão arraigados nas relações materiais, ou seja, de produção [...]” (PACHUKANIS, 2017, p. 104).

Em sentido contrário, Kelsen (1987) afirma que a relação jurídica não se dá, de modo algum, sem os pressupostos de ordem jurídica. Assim, de maneira parecida, Cherchenevitch preleciona que:

\begin{abstract}
Não é por meio da abstração de casos observados que se criou o direito; mas por meio da dedução de regras estabelecidas por alguém e que ficaram conhecidas por nós. A norma sobre o direito de exigir o pagamento de uma dívida não existe porque os credores geralmente o exigem, mas, pelo contrário, os credores exigem o pagamento da dívida porque existe tal norma. (CHERCHENEVITCH apud PACHUKANIS, 2017, p.98).
\end{abstract}

Percebe-se, com efeito, que ambos partem de uma perspectiva dogmática, quer dizer, expressam que não há a possibilidade do surgimento de uma relação jurídica sem a referência da norma escrita, porém, para a perspectiva pachukaniana, é óbvio que a norma objetiva é limitada, sendo, por isso, necessário que se admita que no mundo do ser a relação tenha primazia sobre a norma.

Sobre isso, Pachukanis traz o seguinte exemplo:

Se nenhum devedor pagasse suas dívidas, a regra correspondente deveria, então, ser considerada realmente inexistente, e se quiséssemos, a qualquer custo, sustentar sua existência, deveríamos, de uma maneira ou de outra, fetichizar essa norma. (PACHUKANIS, 2017, p. 98).

Portanto, tal contraste é ainda mais acentuado quando se observa o trabalho do historiador ou sociólogo em contraposição ao do jurista, pois aqueles entendem o direito naquilo que lhe é essencial, quer dizer: o direito sendo concretizado na vida das pessoas, nas cidades, nos estados, no país, e não em entidades abstratas e formais como os juristas estão acostumados a discernir.

Para Pachukanis, o caráter contingencial da norma, como, por exemplo: "Se matar, deve ser preso", que equivale a $[\mathrm{P} \rightarrow \mathrm{Q}]$, necessariamente não significa que ali já exista $\mathrm{o}$ direito, além do que, mesmo que a sentença ganhe um caráter absoluto, isto é: $[\mathrm{P} \leftrightarrow \mathrm{Q}]$, o 
direito não pode ser reduzido ao caráter formal. Por conseguinte, entende-se que o direito não se limita ao fenômeno jurídico estatal.

A título de exemplo, deve-se observar que é recorrente, na história, a ausência da figura estatal e, nem por isso, deixou de existir a relação jurídica entre contratantes. Nesse sentido, Pachukanis demonstra que:

\begin{abstract}
Em semelhantes relações contratuais não garantidas por nenhuma "terceira força", baseava-se todo o sistema feudal. Do mesmo modo, também o direito internacional moderno não conhece nenhuma coerção externamente organizada. Tal gênero de relações jurídicas não garantidas, claro, não se caracteriza pela estabilidade, mas isso não nos dá fundamento nenhum para contestar sua existência. Um direito absolutamente estável, em geral, não existe na natureza; por outro lado, a estabilidade das relações do direito privado no Estado burguês moderno "bem construído" não se apoia de nenhum modo unicamente na polícia e nos tribunais. As dívidas não são saldadas apenas porque seriam "saldadas de qualquer maneira", mas para que o crédito seja conservado no futuro. É evidente o efeito prático que, no mundo dos "negócios", existe na forma do protesto de notas promissórias. (PACHUKANIS, 2017, p.100).
\end{abstract}

E ainda que se tomasse por verdade que o direito apenas existisse no âmbito das normas jurídicas, para Marx, o direito seria uma expressão da sociedade de classes, porque seria um equívoco que se cogitasse que a superestrutura jurídica fosse uma consequência da superestrutura política. Nesse sentido, Pachukanis afirma que:

As relações de produção e sua expressão jurídica formam aquilo que Marx, seguindo Hegel, chamou de sociedade civil. A superestrutura política e, em particular, a organização oficial do Estado constituem um momento secundário e derivado. (PACHUKANIS, 2017, p. 102).

Logo, tendo em vista os aspectos abordados, percebe-se que a sociedade mercantil é o pressuposto para a fundamentação dos princípios basilares da teoria geral do direito. A realização de troca por equivalência é uma condição necessária para o surgimento da relação jurídica e, também, da forma jurídica. O poder político, com seu aparato de estado, não deixa de ser importante, até porque, muito embora não seja a gênese da relação jurídica, este possui o poder de influenciar o desenvolvimento da sociedade capitalista.

Nessa lógica, Vitor Bartoletti Sartori, em Lukács e a Crítica Ontológica ao Direito, afirma que:

O direito seria, em sua essência, um Direito de classe, da classe dominante; o que não impede, porém, que se configure como um fenômeno complexo que não pode ser analisado com vista somente a "essência" classista do Direito. Deve o Direito ser visto tendo em conta a reprodução do complexo social total a qual envolve tanto a 
mediação das classes sociais quanto a linguagem, a divisão do trabalho e o próprio cotidiano. (SARTORI, 2013). [E-Book].

Ou seja, a norma como produto da linguagem, compõe o complexo da vida social, assim quer dizer que não se deve limitar o direito em nenhuma direção como a dogmática jurídica o faz, pois, para ela, tanto a relação jurídica quanto o sujeito de direito são dados pela norma abstrata. Conclui-se então que o esforço de Pachukanis deu-se em demonstrar que o sujeito de direito só existe dadas às condições da sociedade mercantil.

Dessa forma, o Estado burguês não pode, por nenhum modo, se livrar da correlação interna que existe entre a forma-mercadoria e a forma jurídica. Por tal fato, perdura a contradição entre a organização política do Estado, que visa o interesse geral impessoal e o interesse privado. No limite, Jellinek, em Sistemas dos Direitos Públicos Subjetivos, declara que o Estado não é uma estrutura jurídica, de fato, mas que pode ser pensado no sentido jurídico. (JELLINEK, 1919).

Quanto à questão norteada neste capítulo, percebe-se que: a relação jurídica, para os juristas burgueses, é tomada, unicamente, como pressuposto do ordenamento jurídico; com isso, eles limitam o horizonte jurídico e, ao mesmo tempo, omitem que a relação jurídica, na verdade, possui seu real vínculo com a troca por equivalência. Logo, se limitarmos a relação jurídica à norma, negamos a própria forma jurídica.

\section{Considerações finais}

Tendo em vista o que foi examinado na obra Teoria Geral do Direito e Marxismo, de Pachukanis, pode-se dizer que o mérito dele se deu em ter clarificado as contradições pelas quais a ciência jurídica burguesa foi edificada, e, além disso, pelo fato de ter desenvolvido uma análise crítica da forma jurídica burguesa, até então desconhecida.

Pachukanis rompeu com o que tinha sido proposto por Stutchka e Mikhail Reisner em relação à crítica ao direito, uma vez que ele realizou uma crítica que foi pensada e desenvolvida levando em consideração a mesma metodologia empregada por Marx, em Introdução à Crítica da Economia Política. Assim, dialeticamente, analisou as categorias gerais e concretas, e simples e complexas.

Tal análise se destaca também porque não delimitou seu objeto de estudo em relação ao próprio conteúdo do direito, mas sim em relação a sua forma. Por essa via, Pachukanis 
percebeu que havia uma equivalência da forma-mercadoria com a forma jurídica, e que, na verdade, a origem da forma jurídica guardava uma íntima relação com os meios de produção.

Dessa forma, conclui-se que:

a) A categoria sujeito de direito tem a sua origem e desenvolvimento simultâneo ao surgimento e ascensão do Estado capitalista. Sua criação se deu em razão da necessidade da expansão das trocas por equivalência entre homens de diversas regiões. Em razão disso, o homem passa a ser livre, mas somente à medida em que realizar atos de troca, isto é, o homem é livre somente como moeda de troca. Portanto, a categoria sujeito de direito como extensão da forma-mercadoria possibilitou o desenvolvimento da sociedade capitalista, mas não à igualdade material, à emancipação e à dignidade do homem;

b) $\mathrm{O}$ direito e o poder estatal garantem a paz interna, assim permitindo o desenvolvimento e a expansão da forma-mercadoria, e o desenvolvimento e consolidação da economia monetária. Contudo, para isso, ambos carregam uma imagem dúbia, pois o direito, ora se apresenta como o direito do mais forte, ora se confunde com "termos jurídicos"; já o Estado, ora se apresenta como fiador da "vontade geral", ora surge como puro garantidor dos interesses do mercado financeiro. Portanto, o direito e o poder estatal estão a serviço da classe dominante;

c) A moral contribuiu para a consolidação do pensamento jurídico burguês. Disso resultou que o homem moderno, além de ser sujeito de direito e sujeito egoístico, é também sujeito moral. Nesse sentido, norteado pelo imperativo categórico de Kant, a moral moderna tem um caráter ético de cunho universalista, que elimina as contradições em relação à própria realidade. Logo, ao eliminar os costumes locais e regionais, contribuiu para a expansão do sujeito de direito e, consequentemente, do Estado capitalista;

d) A relação jurídica é um fenômeno que ultrapassa os limites da norma em seu sentido objetivo. Em primeiro lugar, verifica-se que o fenômeno jurídico não se limita aos postulados jurídicos como querem os juristas burgueses. Se fosse assim, não se poderia reconhecer a existência de relações contratuais em um período onde 
se mostrou ausente a figura estatal. Em segundo lugar, identificou-se que a dogmática jurídica não consegue delimitar com precisão os interesses do Estado e dos particulares. Em razão disso, conclui-se que a norma objetiva é contraditória por natureza, por isso, a relação jurídica pensada ou não nos limites da norma em sentido objetivo, tem sua origem ligada à forma-mercadoria.

Portanto, tendo em vista a perspectiva pachukaniana sobre o direito, conclui-se que, para a emancipação e libertação do homem, é necessário que o Estado e o direito sejam superados.

\section{Referências}

ENGELS, Friedrich. A origem da Família, da Propriedade Privada e do Estado. Tradução de Leandro Konder. 9. ed. Rio de Janeiro: Civilização Brasileira S.A., 1984.

ENGELS, Friedrich; MARX, Karl. A ideologia alemã (Feuerbach). Tradução de José Carlos Bruni e Marco Aurélio Nogueira. 5. Ed. São Paulo: Hucitec, 1986.

ENGELS, Friedrich; MARX, Karl. Manifesto Comunista. Tradução de Álvaro Pina. 4. ed. São Paulo: Boitempo, 2005.

JELLINEK, Georg. Sistema dos direitos públicos subjetivos. 2. ed. - Tubinga: Mohr, 1919.

KANT, Immanuel. Fundamentação da metafísica dos costumes. Tradução de Paulo Quintela. Lisboa: Edições 70, 2007.

KELSEN, Hans. Teoria pura do direito. Tradução João Baptista Machado; revisão para a edição brasileira: Silvana Vieira. 2. ed. - São Paulo: Martins Fontes, 1987.

MARX, Karl. Grundrisse. Tradução de Mário Duayer e Nélio Schneider. [livro eletrônico] 1. ed. São Paulo: Boitempo, 2011.

MARX, Karl. Miséria da filosofia: resposta à "Filosofia da Miséria" de Pierre-Joseph Proudhon, Rio de Janeiro: Leitura, 1965.

MASCARO, Alysson Leandro. Filosofia do direito. 5. ed. rev., atual. Ampl. - São Paulo: Atlas, 2016.

NAVES, Márcio Bilharinho. Marxismo e direito: um estudo sobre Pachukanis. 1. Reimpressão - São Paulo: Boitempo, 2008. 
PACHUKANIS, Evguiéni B. Teoria geral do direito e marxismo. Tradução Paula Vaz de Almeida; revisão técnica Alysson Leandro Mascaro, Pedro Davoglio. - 1. ed. - São Paulo: Boitempo, 2017.

REZEK, José Francisco. Direito internacional público: curso elementar. 15. ed. rev. E atual. - São Paulo: Saraiva, 2014.

SARTORI, Vitor Bartoletti. Lukács e a crítica ontológica ao direito. [livro eletrônico] 1. ed. - São Paulo: Cortez, 2013.

STANLEY, Paulson L. Fundamentación crítica de la doctrina de Hans Kelsen. Tradução de Luiz Villar Borda. [livro eletrônico] 1. ed. Bogotá: Universidad Externado de Colombia, 2000 . 